\title{
Adsorption Kinetics and Thermodynamics of Water-Insoluble Crosslinked $\beta$-Cyclodextrin Polymer for Phenol in Aqueous Solution
}

\author{
Hui Huang ${ }^{*, 1}$, Yifan Fan ${ }^{1}$, Junwei Wang', Haoqi Gao ${ }^{1}$, and Shiying Tao ${ }^{2}$ \\ ${ }^{1}$ School of Chemical Engineering, Ningbo University of Technology, Ningbo 315016, P. R. China \\ ${ }^{2}$ Division of Engineering, University of Nottingham Ningbo China, Ningbo 315010, P. R. China
}

\begin{abstract}
A water-insoluble $\beta$-cyclodextrin $(\beta$-CD) polymer was synthesized by reacting $\beta$-CD with hexamethylene diisocyanate, and its adsorption kinetics and thermodynamics for phenol from aqueous solution was investigated. The kinetics of adsorption followed the pseudo-second-order model and the adsorption isotherms could be well fitted by the Freundlich adsorption equation. The values of thermodynamic parameters demonstrated that the adsorption was a physisorption in a spontaneous and exothermic process.
\end{abstract}

Keywords: $\beta$-cyclodextrin, adsorption, phenol, kinetics, thermodynamics.

\section{Introduction}

Cyclodextrins (CDs) are torus-shaped cyclic oligosaccharides containing six to twelve glucose units. The individual glucose units are held in a C-1 chair conformation and they are connected by $\alpha$-1,4-glycosidic linkages to form a cyclic structure. ${ }^{1}$ The interior cavity of CDs is relatively hydrophobic and the most characteristic feature of CDs is the ability to form inclusion complexes through host-guest interactions in aqueous solution. ${ }^{2}$ No covalent bonds are broken or formed during the formation of the inclusion complex, the main driving force is the release of enthalpy-rich water from the cavity of CDs, and other forces including van der Waals interactions, hydrogen bonding, hydrophobic interactions, etc. may also contribute. ${ }^{3}$ Binding of guest molecules with $\mathrm{CD}$ is a dynamic equilibrium and the corresponding equilibrium constant dictates the amount adsorbed. ${ }^{3}$ The practically important, industrially produced CDs are composed of six, seven or eight ( $\alpha, \beta$, and $\gamma$, respectively) $D$-glucopyranosyl units. $\beta$-cyclodextrin $(\beta-\mathrm{CD})$ is the most largely produced cyclodextrin and has been widely used as "molecular cages" in the pharmaceutical, agrochemical, food and cosmetical industries. ${ }^{4}$

Based on the special properties and advantages of $\beta-\mathrm{CD}$, water-insoluble $\beta$-CD polymers have also been widely studied in recent years. As has been reported, water-insoluble $\beta$ $\mathrm{CD}$ polymers, which are new type of adsorbent, could effectively adsorb organic molecules and heavy metals in aqueous solution. ${ }^{5-8}$ Phenols (phenol and phenolic compounds) are commonly encountered in aqueous effluents from vari-

*Corresponding Author. E-mail: huihuangnbut@gmail.com ous manufacturing processes, such as oil refineries, coke plants, and phenolic resin plants. ${ }^{9}$ It can contain as little as $10 \mathrm{mg} / \mathrm{L}$ to greater than $5,000 \mathrm{mg} / \mathrm{L}$ of phenol. ${ }^{10}$ The threshold value of phenol in water is $4 \mathrm{mg} / \mathrm{L}$ and U.S. Environmental Protection Agency regulation call for lowering phenol content in the wastewater below $1 \mathrm{mg} / \mathrm{L} .{ }^{11,12}$ Presence of phenol even at low concentration in the industrial waste water adversely affects aquatic as well as human life directly or indirectly when disposed off to public sewage, river or surface water. The ingestion of such contaminated water in the human body causes protein degeneration, tissue erosion and paralysis of the central nervous system together with damage to the kidneys, liver and pancreas. ${ }^{13}$ Water-insoluble $\beta$ $\mathrm{CD}$ polymer, which is synthesized by crosslinking the hydroxyl groups of $\beta$-CD with diisocyanates to form a stable crosslinked network, have already been used by investigators to remove phenol from wastewater, ${ }^{14-16}$ but little is known about the adsorption kinetics and thermodynamics of the $\beta$-CD polymer for phenol.

The aim of this paper is to prepare water-insoluble $\beta$-CD polymer as an adsorbent for the removal of phenol from aqueous solutions through the batch experiments while the adsorption kinetics and thermodynamics of the adsorption process were studied for better understanding of the adsorption behavior.

\section{Experimental}

Materials. $\beta$-CD, obtained from Aladdin Reagent (Shanghai, China), was recrystallized twice from water and dried under vacuum at $110{ }^{\circ} \mathrm{C}$ for $12 \mathrm{~h}$ before use. Dimethyl formamide (DMF) was purchased from Guoyao Chemical 
Reagent (Shanghai, China) and dried by a molecular sieve (4 $\AA$ ) for $12 \mathrm{~h}$. Hexamethylene diisocyanate (HMDI), methanol and phenol of analytical reagent were used directly without further purification as received from Aladdin Reagent.

Characterization. Infrared spectra between 4000 and $500 \mathrm{~cm}^{-1}$ with a resolution of $2 \mathrm{~cm}^{-1}$ were recorded on a FTIR-8300 Fourier transform infrared spectrophotometer (Shimadzu, Japan). The samples were adequately mixed with $\mathrm{KBr}$ powder and pressed into disks. The heating rate of TGA was $20^{\circ} \mathrm{C} / \mathrm{min}$ from ambient to $800{ }^{\circ} \mathrm{C}$. Differential Scanning Calorimetry (DSC) was carried out with a heating rate of $20^{\circ} \mathrm{C} / \mathrm{min}$ in the temperature range of ambient to $400{ }^{\circ} \mathrm{C}$.

Determination of Phenol Concentration. The concentration of phenol was determined with a $7502 \mathrm{C}$ UV-vis spectrophotometer (Shanghai, China) at $270 \mathrm{~nm} .{ }^{17}$ The individual standard was dissolved in distilled water and diluted to form solutions of $10,20,30,40,50 \mathrm{mg} / \mathrm{L}$. The data of the concentration $(c)$ of phenol and absorbance $(A)$ formed a standard curve, namely $A=0.01539 c+0.00119(R=0.99999)$.

Preparation of $\beta$-CD Polymer. Water-insoluble $\beta$-CD polymer was synthesized by reacting $\beta$-CD with HMDI in dried DMF. ${ }^{18} 3 \mathrm{~g}$ of $\beta$-CD was dissolved in $85 \mathrm{~mL}$ of $\mathrm{DMF}$ in a $250 \mathrm{~mL}$ round bottom flask at room temperature. Then, $3.3 \mathrm{~mL}$ of HMDI was added dropwise. After that, the solution was stirred at $80^{\circ} \mathrm{C}$ for $30 \mathrm{~h}$ under $\mathrm{N}_{2}$ protection. The $\beta$-CD polymer was precipitated in a large excess of methanol. The $\beta$-CD polymer was recovered by filtration and dried in vacuum at $80{ }^{\circ} \mathrm{C}$ for $24 \mathrm{~h}$.

Adsorption. Batch adsorption studies were conducted by shaking the flasks for a period of time using a water bath mechanical shaker. The experimental process was as followings: $10 \mathrm{mg}$ of $\beta$-CD polymer was added into a flask containing $50 \mathrm{~mL}$ phenol solution at various concentrations under the temperature of $30^{\circ} \mathrm{C}$ and $\mathrm{pH}$ value of 6.8 , then vibrated at a constant speed of $250 \mathrm{rpm}$ in a shaking water bath. After a period of shaking and contact time, took out the flasks, the supernatants were centrifuged at 2,000 rpm for $10 \mathrm{~min}$ to be clear. The phenol concentration analysis was immediately measured with UV-vis spectrophotometer. Blank sample without adsorbate was used for the comparison under the same conditions.

The equilibrium adsorbed quantity of phenol $\left(Q_{e}\right)$ on $\beta$ $\mathrm{CD}$ polymer is calculated as eq. (1):

$$
Q_{e}=\frac{V \times\left(C_{0}-C_{e}\right)}{m}
$$

where $C_{0}$ and $C_{e}$ are initial and equilibrium concentration of the phenol solution expressed in $\mathrm{mg} / \mathrm{L}$, respectively; $V$ is the volume of phenol solution expressed in $\mathrm{L} ; m$ is the mass of the $\beta$-CD polymer expressed in $\mathrm{g} ; Q_{e}$ is expressed in $\mathrm{mg} / \mathrm{g}$.

Batch Kinetic and Thermodynamic Studies. To investigate the kinetics and thermodynamics of the phenol adsorption on $\beta$-CD polymer, $10 \mathrm{mg} \beta$-CD polymer was added into a flask containing $50 \mathrm{~mL}$ phenol solution at various concentrations with a $\mathrm{pH}$ value of 6.8 , and then vibrated at a constant speed of $250 \mathrm{rpm}$ using a water bath mechanical shaker. In order to study the adsorption isotherms and thermodynamic, $7 \mathrm{~h}$ of contact time were applied to allow attainment of equilibrium at the constant temperature of 15, 20, 30,45 , and $60{ }^{\circ} \mathrm{C}$, respectively. For the kinetic study, the samples were contacted for time intervals at various temperatures. After shaking and contacting, took out the flasks, centrifuged to separate $\beta$-CD polymer and the solution. The phenol concentration of the solution was immediately measured. In the present study, the pseudo-first-order rate model, pseudo-second-order model and intraparticle diffusion model were used to characterize the kinetic models, and activation energy for adsorption was obtained by Arrhenius equation. The Langmuir and Freundlich models were used to describe the equilibrium nature of phenol adsorption onto $\beta$-CD polymer. The equilibrium constants were used to calculate the thermodynamic parameters, such as the change of Gibbs free energy $(\Delta G)$, enthalpy $(\Delta H)$ and entropy $(\Delta S)$.

\section{Results and Discussion}

Characterization of $\beta$-CD Polymer. Figure 1 shows the FTIR spectra of $\beta$-CD (a) and $\beta$-CD polymer (b). Comparing with the spectrum of $\beta-\mathrm{CD}$, the bands at $1717 \mathrm{~cm}^{-1}$ and $1540 \mathrm{~cm}^{-1}$ represented $\mathrm{C}=\mathrm{O}$ groups and $\mathrm{NH}-\mathrm{CO}$ groups, respectively. The $\mathrm{NH}$ groups were observed at the band of $3336 \mathrm{~cm}^{-1}$. All of those peaks proved that $\beta$-CD had reacted with HDMI to form the $\beta$-CD polymer.

Figure 2 shows the TGA and DSC curves of $\beta$-CD, $\beta$-CD polymer and $\beta$-CD polymer adsorbed with phenol. Two different temperature regions of weight loss were observed in the curves of $\beta$-CD polymer and $\beta$-CD polymer adsorbed with phenol, whereas there is only one on $\beta$-CD curve. The first region of the weight loss with a endothermic peak at about $100{ }^{\circ} \mathrm{C}$ could be considered as dehydration of free water, the second region of the weight loss with a exother-

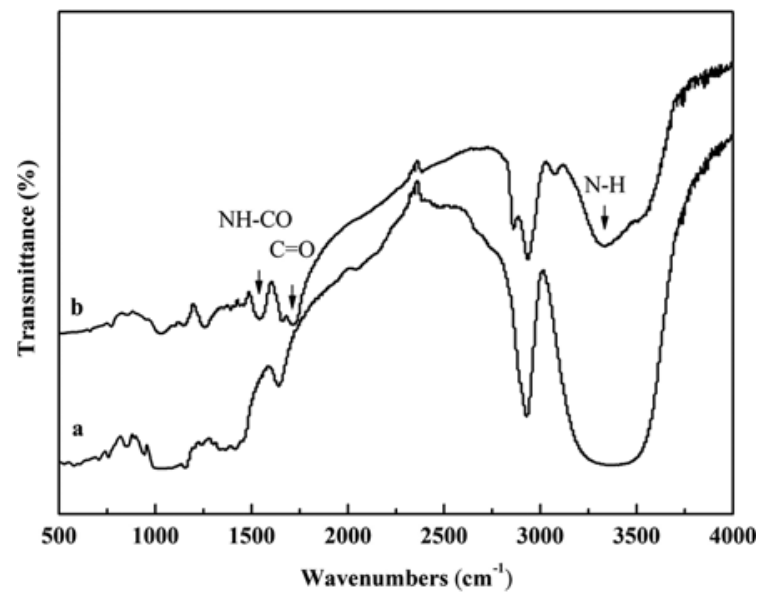

Figure 1. FTIR spectra of $\beta$-CD (a) and $\beta$-CD polymer (b). 


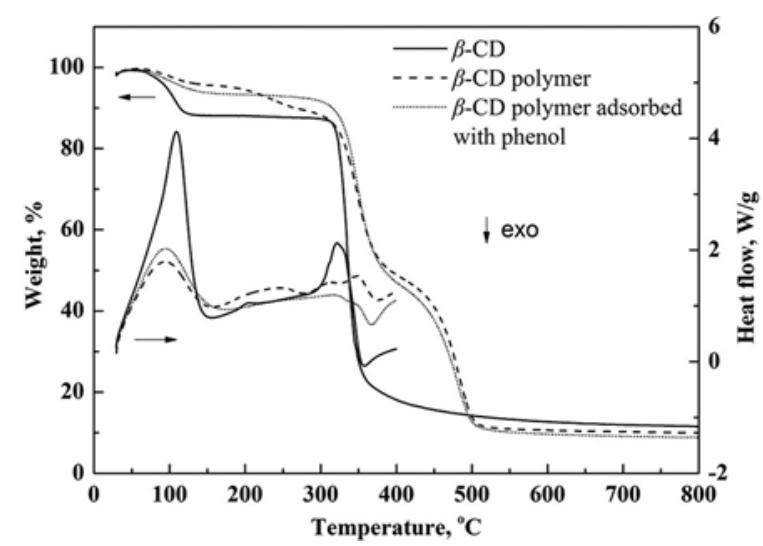

Figure 2. TGA and DSC curves of $\beta$ - $\mathrm{CD}, \beta-\mathrm{CD}$ polymer and $\beta$-CD polymer adsorbed with phenol.

mic peak around $370{ }^{\circ} \mathrm{C}$ was caused by degradation of the $\beta$-CD, and the weight loss at about $450^{\circ} \mathrm{C}$ should be due to the decomposition of carbamide linkages. ${ }^{7}$

Static Adsorption Test. The adsorption of phenol by water-insoluble $\beta$-CD polymer was carried out in a batch reactor with different initial phenol concentrations from 20 to $50 \mathrm{mg} / \mathrm{L}$, the amounts of phenol adsorbed on the $\beta$-CD polymer were increased with the increment of contact time. The adsorption rate is relatively rapid in the first $4 \mathrm{~h}$ time, and adsorption reached equilibrium at $7 \mathrm{~h}$, no remarkable changes were observed for longer contact time (shown in Figure 3). For subsequent experiments, the samples were left for $7 \mathrm{~h}$ to ensure the adsorption equilibrium. The equilibrium time of different initial phenol concentrations was also conducted and the results showed that the initial phenol concentrations had little effect on the adsorption equilibrium time.

Adsorption Kinetics. Knowledge of the adsorption kinetic constitutes the first step in the investigation of the possibility of using an adsorbent for a particular separation

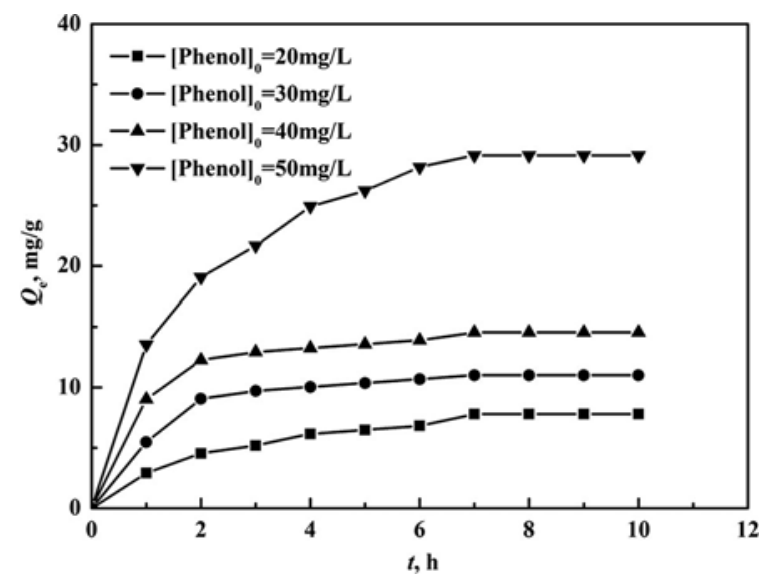

Figure 3. Effect of contact time on phenol adsorption by $\beta-\mathrm{CD}$ polymer at different initial phenol concentrations. task. The pseudo-first-order rate model, pseudo-second-order kinetic model and an intraparticle diffusion kinetic model were used to elucidate the adsorption mechanism.

The pseudo-first-order rate model equation is given as: ${ }^{19,20}$

$$
\ln Q_{1}-\ln \left(Q_{1}-Q_{t}\right)=k_{1} t
$$

where $Q_{1}$ and $Q_{t}$ are the amounts of phenol adsorbed on the adsorbent at equilibrium and at time $t$ in the unit of $\mathrm{mg} / \mathrm{g}$, and $k_{1}\left(\mathrm{~h}^{-1}\right)$ is the rate constant of the first-order adsorption. The straight-line plots of $\ln \left(Q_{1}-Q_{t}\right)$ against $t$ were used to determine rate constant $k_{1}$.

The pseudo-second-order model may also describe the kinetics of the adsorption of phenol on $\beta$-CD polymer. Kinetic rate law could be rewritten as: ${ }^{21-24}$

$$
\frac{t}{Q_{t}}=\frac{1}{k_{2} Q_{2}^{2}}+\frac{t}{Q_{2}}
$$

where $k_{2}$ is the rate constant of second-order adsorption in the unit of $\mathrm{g} \cdot \mathrm{mg}^{-1} \cdot \mathrm{h}^{-1}, Q_{t}$ is the amount of phenol adsorbed on the adsorbent at time $t$ in the unit of $\mathrm{mg} / \mathrm{g}$ and $Q_{2}$ is the maximum adsorption capacity for the pseudo-second-order adsorption in the unit of $\mathrm{mg} / \mathrm{g}$. The straight line plots of $t / Q_{t}$ against $t$ could be tested to obtain rate parameters.

For a solid liquid adsorption process, to analyze the rate controlling steps is very beneficial for elaborating the adsorption mechanism. The intraparticle diffusion model can't describe the whole adsorption process, but it can reflect the speed limit factor before the adsorption balance being reached in a certain degree. The intraparticle diffusion model is expressed as: $:^{25,26}$

$$
Q_{t}=k_{p} t^{1 / 2}+C
$$

where $Q_{t}$ is the amount of phenol adsorbed at time $t$ in the unit of $\mathrm{mg} / \mathrm{g}$. $C$ is the intercept and $k_{p}$ is the intraparticle dif-

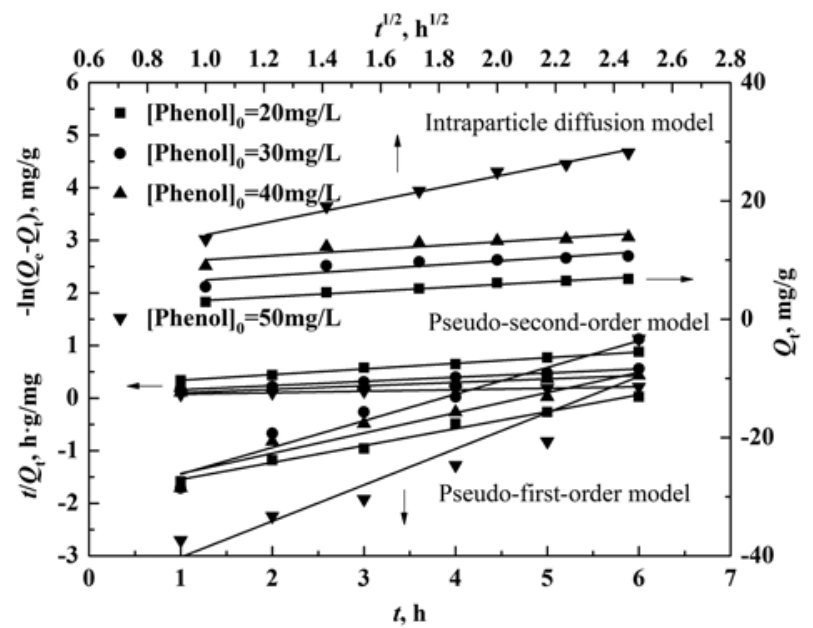

Figure 4. Pseudo-first-order, pseudo-second-order kinetic model and intraparticle diffusion model for adsorption of phenol on $\beta$ CD polymer. 
Table I. Adsorption Kinetic Parameters at $30{ }^{\circ} \mathrm{C}$ for Different Kinetic Models

\begin{tabular}{ccccccccccc}
\hline \multirow{2}{*}{$\begin{array}{c}\text { Initial Phenol } \\
\text { Concentration }(\mathrm{mg} / \mathrm{L})\end{array}$} & $\begin{array}{c}Q_{e, e x p} \\
(\mathrm{mg} / \mathrm{g})\end{array}$ & \multicolumn{3}{c}{ Pseudo-First-Order Model } & \multicolumn{3}{c}{ Pseudo-Second-Order Model } & \multicolumn{3}{c}{ Intraparticle Diffusion Model } \\
\cline { 3 - 13 } & $k_{1}\left(\mathrm{~h}^{-1}\right)$ & $Q_{1}(\mathrm{mg} / \mathrm{g})$ & $R^{2}$ & $k_{2}\left(\mathrm{~g} \cdot \mathrm{mg}^{-1} \cdot \mathrm{h}^{-1}\right)$ & $Q_{2}(\mathrm{mg} / \mathrm{g})$ & $R^{2}$ & $k_{\mathrm{p}}\left(\mathrm{g} \cdot \mathrm{mg}^{-1} \cdot \mathrm{h}^{-1 / 2}\right) C(\mathrm{mg} / \mathrm{g})$ & $R^{2}$ \\
\hline 20 & 7.79 & 0.3219 & 1.87 & 0.9908 & 0.0488 & 9.34 & 0.9962 & 0.5089 & 2.69 & 0.9730 \\
30 & 11.01 & 0.5071 & 7.04 & 0.9579 & 0.0765 & 12.63 & 0.9912 & 3.4447 & 3.20 & 0.8087 \\
40 & 14.55 & 0.3847 & 6.15 & 0.9386 & 0.1101 & 15.28 & 0.9986 & 7.0420 & 3.02 & 0.8270 \\
50 & 28.49 & 0.6873 & 40.93 & 0.8838 & 0.0157 & 35.88 & 0.9958 & 4.3565 & 9.92 & 0.9870 \\
\hline
\end{tabular}

fusion rate constant in the unit of $\mathrm{mg} /\left(\mathrm{g} \cdot \mathrm{min}^{1 / 2}\right)$. Vales of $k_{p}$ and $C$ were calculated from the plot of $Q_{t}$ against $t^{1 / 2}$.

As shown in Figure 4, the straight-line plots of $-\ln \left(Q_{1}-Q_{t}\right)$ against $t$ for the pseudo-first-order model, $t / Q_{t}$ against $t$ for the pseudo-second-order model and $Q_{t} v s . t^{1 / 2}$ for the intraparticle diffusion model of phenol adsorption onto $\beta$-CD polymer have been tested to obtain the rate parameters at $30{ }^{\circ} \mathrm{C}$ (the plots for other temperatures were not shown). The adsorption kinetic parameters of phenol under the experimental conditions were summarized in Table I. The correlation coefficient values $\left(R^{2}\right)$ for the first-order kinetic model, pseudo-second-order kinetic model and the intraparticle diffusion kinetic model were range from 0.8838 to 0.9908 , 0.9912 to 0.9986 , and 0.8087 to 0.9870 , respectively. The high coefficients values $\left(R^{2}\right)$ and similarity between the experimental capacities at equilibrium and the calculated capacities from the model indicate that the pseudo-second-order model fits the experimental data quite well. It can be also observed from Table I and Figure 4 that the values of $C$ in intraparticle diffusion model were not zero and the plots did not pass through the origin, which indicating that intraparticle diffusion was involved in the adsorption process but it was not the only rate-controlling step and some degree of boundary layer effect may also played an important role..$^{27,28}$

It was possible to obtain the activation energy for adsorption by employing Arrhenius equation ${ }^{29}$ for the rate constants based on the results of Figure 5. It shows as follows:

$$
\ln k=\ln A-\frac{E_{a}}{R T}
$$

where $k$ is the rate constant of second-order adsorption in the unit of $\mathrm{g} \cdot \mathrm{mg}^{-1} \cdot \mathrm{h}^{-1} . A$ is the frequency factor, $\mathrm{h}^{-1} . E_{a}$ is the activation energy, $\mathrm{kJ} / \mathrm{mol} . R$ is the ideal gas constant and $T$ is the thermodynamic temperature, $\mathrm{K}$.

Thus, $E_{a}$ could be got from the slope of the line plotting $\ln$ $k$ vs. $1 / T$ and the estimated $E_{a}$ for phenol adsorption on $\beta$ CD polymer was $6.164 \mathrm{~kJ} / \mathrm{mol}$. The estimated $E_{a}$ is very low $(<40 \mathrm{~kJ} / \mathrm{mol}),{ }^{30}$ and the adsorption of phenol on $\beta$-CD polymer could be considered as a physical sorption process.

Adsorption Isotherms. Equilibrium data, commonly known as adsorption isotherm, is important to develop an equation that accurately represents the results and can be used in design of adsorption systems. An additional potential use of adsorption isotherms is to calculate the thermodynamic

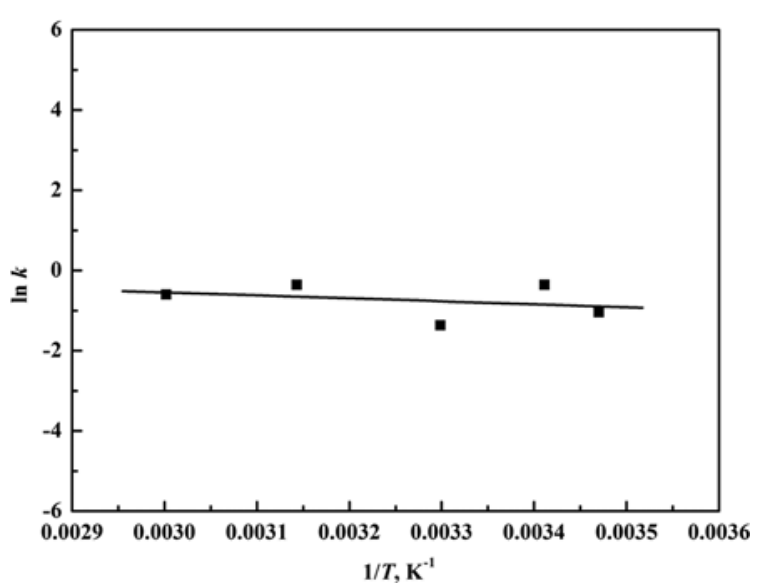

Figure 5. Plots of $\ln k v s .1 / T$.

parameters. Several models have been published in the literatures to describe experimental data of adsorption equilibriums. Among them, the Langmuir and Freundlich models are the most frequently employed models. In this study, the Langmuir and Freundlich isotherms were selected to describe the equilibrium between the adsorbed phenol molecular on $\beta$-CD polymer and phenol molecular in solution at the constant temperatures.

The Langmuir model is based on a theoretical model and assumes that the maximum adsorption corresponds to a monolayer saturated with adsorbate molecules on the adsorbent surface that is energetically homogeneous from the adsorptive point of view. It is represented as follows: ${ }^{31,32}$

$$
\frac{1}{Q_{e}}=\frac{1}{Q_{m}}+\frac{1}{Q_{m} K_{L} C_{e}}
$$

where $Q_{m}$ is the maximum adsorption at monolayer in the unit of $\mathrm{mg} / \mathrm{g} . C_{e}$ is the equilibrium concentration of phenol. $Q_{e}$ is the amount of phenol adsorbed per unit mass of $\beta$-CD polymer at equilibrium concentration. $K_{L}$ is the Langmuir coefficient related to the affinity of binding sites in the unit of $\mathrm{L} / \mathrm{mg}$. The Langmuir isotherm constants are determined from the plots of $1 / Q_{e}$ against $1 / C_{e}$ (see Figure 6).

The Freundlich model also could be used to describe equilibrium adsorption isotherms as an empirical model that considers heterogeneous adsorptive energies on the adsorbent surface. It is represented as follows: $:^{33,34}$ 


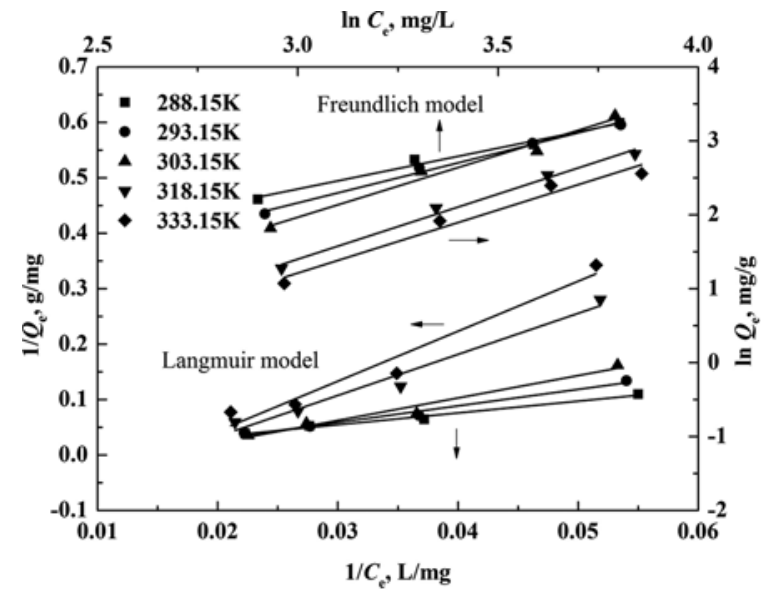

Figure 6. The Langmuir and Freundlich isotherm plot for phenol adsorption on $\beta$-CD polymer at different temperatures.

$$
\ln Q_{e}=\ln K_{F}+\frac{1}{n} \ln C_{e}
$$

where the Freundlich isotherm constants $n$ and the equilibrium constant $K_{F}$ are determined from the plots of $\ln Q_{e}$ against $\ln C_{e}$ (see Figure 6).

The Langmuir and Freundlich isotherm constants evaluated from the isotherms with the correlation coefficients are listed in Table II. All of the $R^{2}$ values exceed 0.95 for both the Freundlich and Langmuir models, suggesting that both models closely fitted the experimental results. At the same time, the negative values of $K_{L}$ and $Q_{m}$ for Langmuir model demonstrated that the Freundlich isotherm fitted better than the Langmuir isotherm. The values of $K_{F}$ were 0.3807 , $0.1498,0.0462,0.0205$, and $0.0201 \mathrm{~L} / \mathrm{mg}$ at $15,20,30,45$, and $60{ }^{\circ} \mathrm{C}$, respectively. $K_{F}$ decreased with the increase in the temperatures, revealing that the adsorption capacity of phenol on $\beta$-CD polymer decreased with the increase in the temperatures and the adsorption was exothermic.

Adsorption Thermodynamics. Values of thermodynamic parameters are the actual indicators for practical application of a process. Generally, the Gibbs free energy $(\Delta G)$, enthalpy $(\Delta H)$ and entropy $(\Delta S)$ changes was calculated from data interpolated using the best fitting isotherm. Therefore, the Freundlich isotherm was used to calculate the thermodynamic parameters in this study.

Table II. Langmuir and Freundlich Isotherm Constants for Phenol Adsorption on $\beta$-CD Polymer

\begin{tabular}{ccccccc}
\hline \multirow{2}{*}{$T(\mathrm{~K})$} & \multicolumn{3}{c}{ Langmuir Model } & \multicolumn{3}{c}{ Freundlich Model } \\
\cline { 2 - 7 } & $Q_{m}(\mathrm{mg} / \mathrm{g})$ & $K_{L}(\mathrm{~L} / \mathrm{mg})$ & $R^{2}$ & $K_{F}$ & $n$ & $R^{2}$ \\
\hline 288.15 & -110.1322 & -0.0043 & 0.9842 & 0.3807 & 0.9053 & 0.9845 \\
293.15 & -32.8947 & -0.0102 & 0.9840 & 0.1498 & 0.7392 & 0.9914 \\
303.15 & -17.0474 & -0.0145 & 0.9721 & 0.0462 & 0.5951 & 0.9793 \\
318.15 & -8.3897 & -0.0155 & 0.9707 & 0.0205 & 0.5675 & 0.9891 \\
333.15 & -7.2892 & -0.0152 & 0.9587 & 0.0201 & 0.5859 & 0.9686 \\
\hline
\end{tabular}

The change in Gibbs free energy $(\Delta G)$, enthalpy $(\Delta H)$ and entropy $(\Delta S)$ were estimated using following equations: ${ }^{35}$

$$
\begin{aligned}
& \ln \frac{1}{C_{e}}=-\frac{\Delta H}{R T}+K_{0} \\
& \Delta G=n R T \\
& \Delta S=\frac{\Delta H-\Delta G}{T}
\end{aligned}
$$

where $C_{e}$ is the equilibrium phenol concentration of the solution in the unit of $\mathrm{mg} / \mathrm{L}, n$ is the fitting constant of Freundlich exponent, $R$ is the gas constant with the value of $8.314 \mathrm{~J} /(\mathrm{mol} \cdot \mathrm{K}), T$ is the temperature in the unit of $K$, and $K_{0}$ is a constant. The $\Delta H$ of the adsorption could be calculated from the slope of $\ln 1 / C_{e}$ against $1 / \mathrm{T}$ (Figure 7).

Table III presents the thermodynamic parameters at various initial phenol concentrations in aqueous solution. Values of the enthalpy changes $(\Delta H)$, always negative, are indicative of an exothermic process, and their magnitudes $(<40 \mathrm{~kJ} / \mathrm{mol}$ ) show the adsorption of phenol on $\beta$-CD polymer within the range investigations in this study to be a physical adsorption in nature. ${ }^{36}$ The positive entropy changes $(\Delta S)$ indicated that the degrees of freedom increased at the solid-liquid interface during the adsorption. The obtained Gibbs free energy changes $(\Delta G)$ are negative at all of the tested temperatures range from 15 to $60^{\circ} \mathrm{C}$, confirming that the adsorption of phenol on $\beta$-CD polymer is spontaneous and thermodynamically favorable. The values of $\Delta G$ are among -2.17 and $-1.50 \mathrm{~kJ} / \mathrm{mol}$, between -20 and $0 \mathrm{~kJ} / \mathrm{mol}$ of a physisorption process,${ }^{37}$ which further indicating that the physisporption might dominate the adsorption of phenol on $\beta$-CD polymer.

Desorption. Regeneration capacity is one of important goals for developing adsorbent. $\beta$-CD polymer could be easily regenerated by extraction with ethanol and the complexing abilities of the $\beta$-CD polymer remain more than $90 \%$ in contrast to the first adsorption capacity after 5 regeneration cycles.

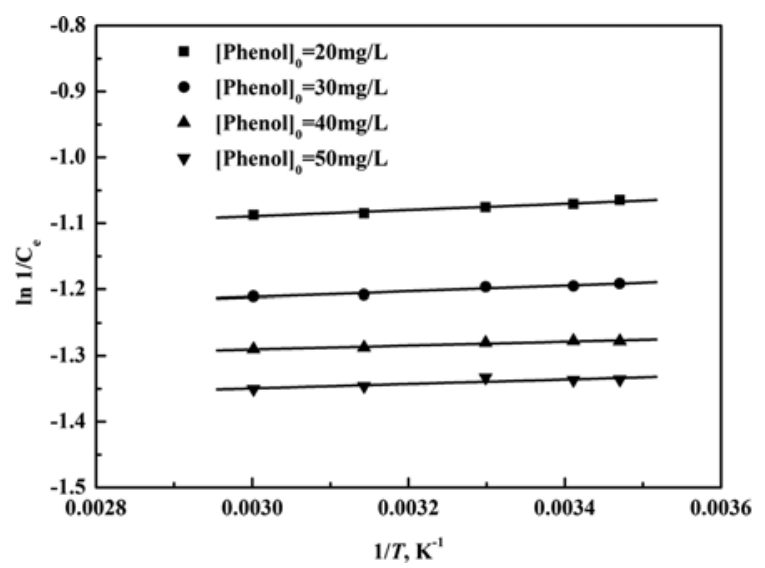

Figure 7. Enthalpy determination curves for the adsorption of phenol on $\beta$-CD polymer at different initial phenol concentrations. 
Table III. Thermodynamic Parameters of Adsorption of Phenol on $\beta$-CD Polymer

\begin{tabular}{|c|c|c|c|c|c|c|c|c|c|c|c|}
\hline \multirow{2}{*}{$\begin{array}{c}\text { Initial Phenol } \\
\text { Concentration }(\mathrm{mg} / \mathrm{L})\end{array}$} & \multirow{2}{*}{$\Delta H(\mathrm{~J} / \mathrm{mol})$} & \multicolumn{5}{|c|}{$\Delta G(\mathrm{~kJ} / \mathrm{mol})$} & \multicolumn{5}{|c|}{$\Delta S(\mathrm{~J} /(\mathrm{K} \cdot \mathrm{mol}))$} \\
\hline & & $15^{\circ} \mathrm{C}$ & $20^{\circ} \mathrm{C}$ & $30^{\circ} \mathrm{C}$ & $45^{\circ} \mathrm{C}$ & $60^{\circ} \mathrm{C}$ & $15^{\circ} \mathrm{C}$ & $20^{\circ} \mathrm{C}$ & $30^{\circ} \mathrm{C}$ & $45^{\circ} \mathrm{C}$ & $60^{\circ} \mathrm{C}$ \\
\hline 20 & -396.25 & \multirow{4}{*}{-2.17} & \multirow{4}{*}{-1.80} & \multirow{4}{*}{-1.50} & \multirow{4}{*}{-1.50} & \multirow{4}{*}{-1.62} & 6.15 & 4.79 & 3.64 & 3.47 & 3.68 \\
\hline 30 & -351.31 & & & & & & 6.31 & 4.95 & 3.79 & 3.61 & 3.82 \\
\hline 40 & -244.88 & & & & & & 6.68 & 5.31 & 4.14 & 3.95 & 4.14 \\
\hline 50 & -278.57 & & & & & & 6.56 & 5.20 & 4.03 & 3.84 & 4.04 \\
\hline
\end{tabular}

\section{Conclusions}

In this study, water-insoluble $\beta$-CD polymer was synthesized by reacting $\beta$-CD with hexamethylene diisocyanate, and its adsorption kinetics and thermodynamics for phenol from aqueous solution was investigated with variations in phenol concentration and contact time at the temperature range of 15 to $60{ }^{\circ} \mathrm{C}$. The adsorption process reached equilibrium in $7 \mathrm{~h}$ of contact, and the increase in the initial phenol concentration and decrease in contact temperature could increase the phenol adsorption capacity. The kinetic data fitting results showed that the adsorption process followed the pseudo-second-order kinetic model, and the equilibrium adsorption isotherm could be well described by the Freundlich model. Thermodynamic calculations showed that the enthalpy changes and Gibbs free energy changes were negative, and entropy changes were positive, indicating that the adsorption process was physisorption, spontaneous and exothermic. The $\beta$-CD polymer was easily recovered by ethanol as desorption solvent.

Acknowledgments. This work was supported by K.C. Wong Education, Hong Kong, Zhejiang Provincial Natural Science Foundation of China (LQ12B06002), the Start-up Foundation of Ningbo University of Technology (0080011540050), and the Foundation for Innovative Research Team of Organic Polymer Materials and Engineering of Ningbo (2011B82002).

\section{References}

(1) E. Engeldinger, D. Armspach, and D. Matt, Chem. Rev., 103, 4147 (2003).

(2) M. V. Rekharsky and Y. Inoue, Chem. Rev., 98, 2035 (1998).

(3) E. M. M. Del Valle, Process Biochem., 39, 1033 (2004).

(4) E. Bilensoy, Cyclodextrins in Pharmaceutics, Cosmetics, and Biomedicine: Current and Future Industrial Applications, John Wiley \& Sons, Inc., New Jersey, 2011.

(5) N. Li, X. Wei, Z. Mei, X. Xiong, S. Chen, M. Ye, and S. Ding, Carbohydr. Res., 346, 1721 (2011).

(6) J. B. Xiao, X. Q. Chen, and H. Z. Yu, Macromol. Res., 14, 443 (2006).

(7) Z. Y. Sun, G. P. Cao, H. Lv, L. Zhao, T. Liu, L. Montastruc, and N. Iordan, J. Appl. Polym. Sci., 114, 3882 (2009).

(8) Z. Y. Sun, M. X. Shen, G. P. Cao, J. Deng, Y. Liu, T. Liu, L. Zhao, and W. K. Yuan, J. Appl. Polym. Sci., 118, 2176 (2010).
(9) N. S. Kumar, M. V. Subbaiah, A. S. Reddy, and A. Krishnaiah, J. Chem. Technol. Biotechnol., 84, 972 (2009).

(10) M. A. Dabhade, M. B. Saidutta, and D. V. R. Murthy, Afr. $J$. Biotechnol., 8, 644 (2009).

(11) R. Qadeer and A. H. Rehan, Turk. J. Chem., 26, 357 (2002).

(12) US-EPA, Toxicological Review of Phenol, 635.R02.006 (2002).

(13) Q. Y. Chen, J. B. Xiao, X. Q. Chen, X. Y. Jiang, H. Z. Yu, and M. Xu, Adsorpt. Sci. Technol., 24, 547 (2006).

(14) H. Yamasaki, Y. Makihata, and K. Fukunage, J. Chem. Technol. Biotechnol., 83, 991 (2008).

(15) H. Yamasaki, Y. Makihata, and K. Fukunaga, J. Chem. Technol. Biotechnol., 81, 1271 (2006).

(16) H. Yamasaki, H. Matsui, and K. Fukunaga, Jpn. Environ. Conser. Eng., 36, 50 (2007)

(17) Q. M. Wei and T. Nakato, Microporous Mesoporous Mater., 26, 84 (2006).

(18) M. Bhaskar, P. Aruna, R. J. G. Jeevan, and G. Radhakrishnan, Anal. Chim. Acta, 509, 39 (2004).

(19) Y. S. Ho, Scientometrics, 59, 171 (2004).

(20) S. Lagergren, Kungliga Svenska Vetenskapsakademiens. Hanglingar, 24, 1 (1898).

(21) Y. S. Ho and G. McKay, Trans. IChemE, 76, 183 (1998).

(22) Y. S. Ho and G. McKay, Process Biochem., 34, 451 (1999).

(23) Y. S. Ho and G. McKay, Trans. IChemE, 76, 332 (1998).

(24) Y. S. Ho and G. McKay, Resour. Conserv. Recycling, 25, 171 (1999).

(25) F. C. Wu, R. L. Tseng, and R. S. Juang, Chem. Eng. J., 153, 1 (2009).

(26) W. J. Weber and J. C. Morris, J. Sanit. Eng. Div. Am. Soc. Civ. Eng., 89, 31 (1963).

(27) G. Crini, H. N. Peindy, F. Gimbert, and C. Robert, Sep. Sci. Technol., 53, 97 (2007).

(28) N. Li and X. M. Lei, J. Incl. Phenom. Macrocycl. Chem., 74, 167 (2012).

(29) K. J. Laidler, J. Chem. Educ., 61,494 (1984).

(30) A. Breeuwsma, J. Colloid Interface Sci., 43, 437 (1973).

(31) I. Langmuir, J. Am. Chem. Soc., 40, 1361 (1918).

(32) I. Langmuir, J. Am. Chem. Soc., 38, 2221 (1916).

(33) H. M. F. Freundlich, Z. Phys. Chem., 57, 385 (1906).

(34) Y. S. Ho, J. F. Porter, and G. McKay, Water Air Soil Pollut, 141, 1 (2002).

(35) R. A. Garcia-Delgado, L. M. Cotouelo-Minguez, and J. J. Rodriguez, Sep. Sci. Technol., 27, 975 (1992).

(36) M. Kara, H. Yuzer, E. Sabah, and M. S. Celik, Water Res., 37, 224 (2003).

(37) M. J. Jaycock and G. D. Parfitt, Chemistry of Interfaces, Ellis Horwood, Chichester, 1981. 